\title{
"Wild-type" gastrointestinal stromal tumors: a problem to define
}

\author{
Julio C. López-Valdés ${ }^{1,2 *}$, Eduardo González-Negrete ${ }^{3}$, Jorge A. Medina-Medina4, \\ Arturo Cervantes-Bárcenas², Joaquín García-Serrano², and Ricardo Morales-Martínez ${ }^{4}$ \\ ${ }^{1}$ Department of Research, School of Medicine of Tampico "Dr. Alberto Romo Caballero"Autonomous University of Tamaulipas, Tampico, Tamaulipas; \\ ${ }^{2}$ Regional Hospital Río Blanco, Río Blanco, Veracruz; ${ }^{3}$ Department of Postgraduate Education Autonomous University of Mexico, Mexico City, \\ Mexico; ${ }^{4}$ Department of Oncological Surgery, National Medical Center "Hospital 20 de Noviembre", Instituto de Seguridad y Servicios Sociales de \\ Ios Trabajadores del Estado (ISSSTE), Mexico City, Mexico
}

\begin{abstract}
Introduction: Due to progress in immunohistochemistry and the growing understanding of gastrointestinal stromal tumors (GISTs), it has been possible to elucidate certain aspects related to this group of neoplasms, but, given its unusual characteristics, new questions arose. Such is the case of the subtype called "wild-type GIST" (WT-GIST) (GIST, which lacks the mutations (KIT or PDGFRA). They represent a therapeutic challenge due to their resistance to agents that act as a molecular target for the disease. The aim of this study was to make a brief analysis of the WT-GIST. Material and methods: A bibliographic review of the PubMed and ResearchGate database was conducted. The MeSH terms "GIST"AND "Wild-type"OR "pediatric" were used. Studies published between 2005 and 2018 were cataloged, and originals, reviews, and editorials in English were selected. Given that the aim of the study was bibliographical, there was no need to perform a formal statistical analysis. Results: When comparing WT-GISTS with the classic phenotype, wild tumors have a set of non-specific heterogeneous mutations such as BRAF, NF-1, KRAS, CBL, PI3K3CA, or protein succinate dehydrogenase (subunits $A, B, C$, and $D$ ), this last one being the most common. Conclusions: Nowadays, given the unique and indolent characteristics of this group of neoplasms, there is a need for the correct diagnosis and limitation of the subgroup to which they belong, to reduce the risk of failure for the various existing therapeutic pathways.
\end{abstract}

Key words: Gastrointestinal stromal tumors. Wild-type gastrointestinal stromal tumors. KIT. Imatinib.

\section{Introduction}

Gastrointestinal stromal tumors (GISTs) are the most common mesenchymal neoplasms. Their incidence ranges from $4.3-6.8$ to 19 - 22 cases per million (cpm) inhabitants, solely depending on the studied geographical zone ${ }^{1,2}$. In Latin America, the lack of data for each of the Hispanic populations is evident; nevertheless, Medina-Medina et al. ${ }^{3}$ reported a probable incidence of $9.7 \mathrm{cpm}$ for Mexican population, which is higher than that reported by colleagues in the US and Canada, and showing an average age under 56 years for its diagnosis in Mexico, as well as a slight predominance of this neoplasm in females ${ }^{3,4}$.

In recent years, with advances in the field of immunohistochemistry and a growing understanding of the disease, certain lesser-known aspects related to this group of neoplasms have been clarified. However, given its unusual circumstances, new questions arose
Correspondence:

*Julio C. López-Valdés

E-mail: jc.lopz@live.com

DOI: 10.24875/RMU.20000128
Available online: $17-03-2020$

Date of reception: 17-09-2019

Date of acceptance: 22-01-2020
Medicina Universitaria. 2020;22(1):38-43

www.medicinauniversitaria.org (http://creativecommons.org/licenses/by-nc-nd/4.0/). 


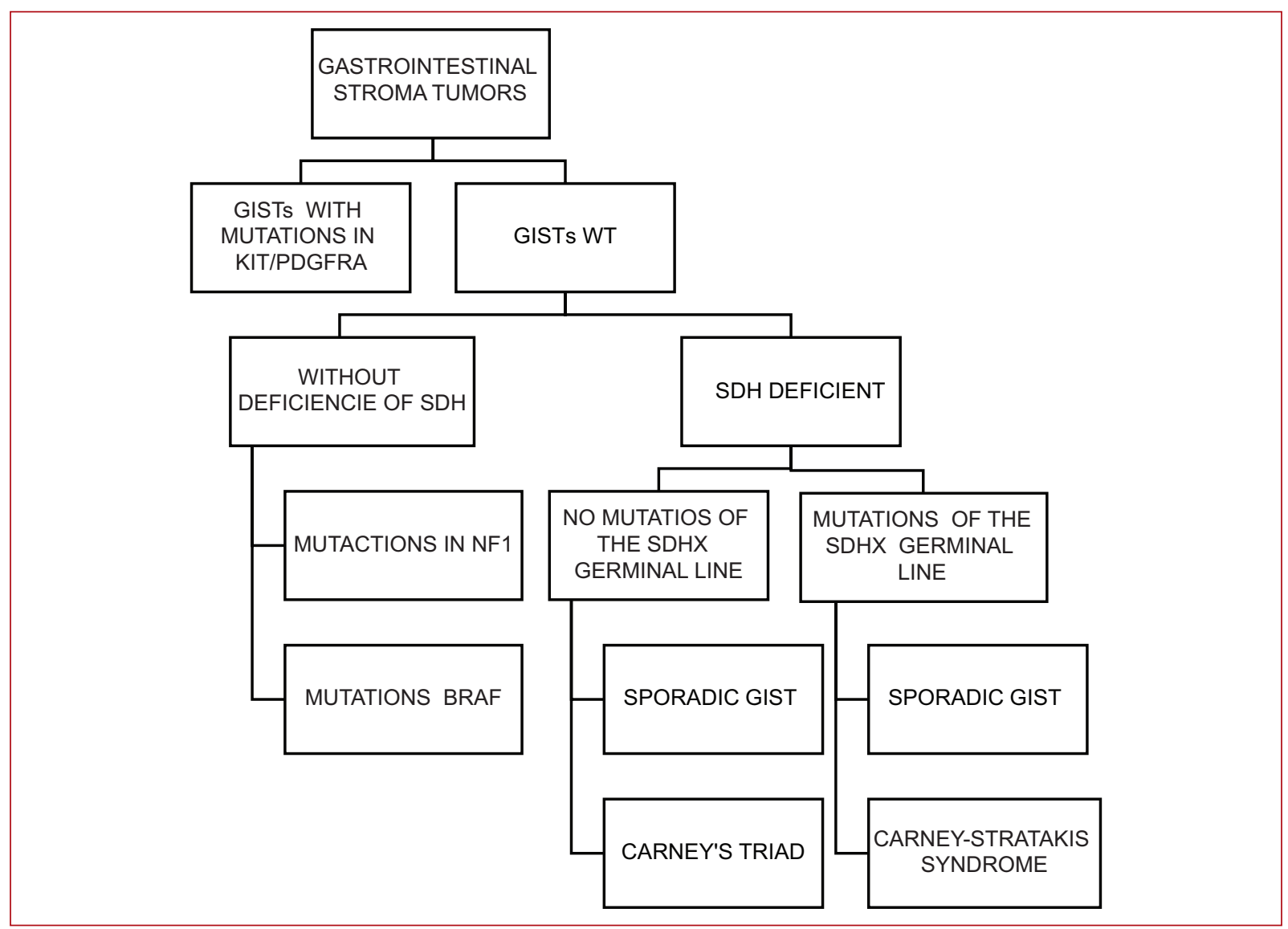

Figure 1. Classification of gastrointestinal tumors.

surrounding this entity; the case of the subtype "wild GIST" or "wild-type GIST" (WT-GIST), which lacks those mutations (KIT or PDGFRA) known to this day for this type of tumor, and represents a therapeutic challenge because of its resistance to agents which act as molecular targets for the disease (i.e., imatinib mesylate) ${ }^{5,6}$.

Within the literature in Spanish, there are a limited number of articles, though not to say non-existing, about the GIST subtype. Therefore, it is necessary to conduct a brief analysis of world literature.

\section{WT-GIST epidemiology}

Conversely to the original subtype, the age for WTGIST onset is usually much lower, with most cases being found in patients under 20 years of age ${ }^{5}$. While its incidence has not been described in its entirety, estimations suggest that approximately $80-85 \%$ of WTGIST occurs in children and adolescents, and 10-15\% in adults. WT-GIST lacks KIT or PDGFRA gene mutations; additionally, different authors state that GIST during a pediatric age represents $<1-2 \%$ of the total GIST in the world, while the United Kingdom's National
Registry of Childhood Tumors estimated an incidence of $0.4 \mathrm{cpm}$ under 14 years old $2,6-10$.

Contrary to most reported cases of the classic phenotype, they tend to predominate in female patients. However, the most common location (stomach and small intestine), as well as the signs and symptoms for its debut are the same as in adult life $e^{1,2,8,11}$. These types of tumors tend to be characterized by either evident or hidden gastrointestinal hemorrhage $(28 \%)$, abdominal pain (8 $-17 \%)$, asymptomatic abdominal mass $(5 \%)$, or acute abdominal pain (2 - 14\%). They have also been described as incidental findings (13 - 18\%) during a necropsy surgical intervention ${ }^{12,13}$.

Surgery remains the standard WT-GIST treatment, since it is the only modality of tumors that are resistant to conventional cytotoxic chemotherapy, and surgery offers a potential definitive cure in patients with resectable tumors ${ }^{14}$.

Certainly, being a "weird" entity, the available data regarding its physiopathology and etiology are insufficient to establish a common cause among this group. Most cases are a sporadic occurrence, even though it has been established that some of these tumors have 
Table 1. Molecular and clinical characteristics of the different presentations of WT-GIST with defects in succinate dehydrogenase protein and its subunits

\begin{tabular}{|c|c|c|c|c|c|c|c|}
\hline IHO & $\begin{array}{l}\text { Other } \\
\text { tests for } \\
\text { IHC }\end{array}$ & Type & Age & Sex & Other characteristics & $\begin{array}{l}\text { IGF1 } \\
\text { (IHO) }\end{array}$ & Differences \\
\hline \multirow[t]{2}{*}{ SDHB (+) } & & Sporadic & $6^{\text {th }}$ decade & Indistinct & $\begin{array}{l}\text { - Unique tumors, without } \\
\text { lymphatic spread } \\
\text { - Clinical course similar to the } \\
\text { classic GIST phenotype }\end{array}$ & $(-)$ & $\begin{array}{l}\text { Absence of mutations in } \\
\text { SDH genes } A, B, C, D\end{array}$ \\
\hline & & $\begin{array}{l}\text { NF-1\& } \\
(1-2 \%)\end{array}$ & Indistinct & Indistinct & $\begin{array}{l}\text { - Multiple small tumors } \\
\text { - Mainly in the small intestine } \\
\text { - Low mitotic activity } \\
\text { - Not sensitive to imatinib }\end{array}$ & $(-)$ & $\begin{array}{l}\text { Absence of mutations in } \\
\text { SDH genes } A, B, C \text {, and } D \\
\text { Loss of loci } 14 q \text { and } 22 q\end{array}$ \\
\hline \multirow[t]{5}{*}{$\begin{array}{l}\text { SDHB }(-) \\
5-7 \%\end{array}$} & \multirow[t]{4}{*}{ SDHA (+) } & Sporadic & $\begin{array}{l}\text { Rare in } \\
\text { children }\end{array}$ & Male & $\begin{array}{l}\text { - Indolent clinical course } \\
\text { - Mainly in the stomach } \\
\text { - Unpredictable behavior }\end{array}$ & $(+)^{*}$ & $\begin{array}{l}\text { Mutations in SDH B, C, } \\
\text { and D genes Rarely in } \\
\text { SDH A }\end{array}$ \\
\hline & & Pediatric & 14 years & Female & \multirow{4}{*}{$\begin{array}{l}\text { - Mainly in the stomach } \\
\text { - Epithelioid morphology } \\
\text { - Multifocal GISTs } \\
\text { - Unpredictable behavior } \\
\text { - Metastasis to lymph nodes } \\
\text { - Indolent clinical course, } \\
\text { even when there is } \\
\text { metastasis } \\
\text { - Probably insensitive to } \\
\text { imatinib, but sensitive to } \\
\text { VEGFRI }\end{array}$} & \multirow[t]{4}{*}{$(+)^{*}$} & \\
\hline & & $\mathrm{TC}^{\&}$ & Indistinct & Female & & & $\begin{array}{l}\text { Absence of mutations in } \\
\text { SDH Association of } \\
\text { paraganglioma and } \\
\text { pulmonary chondromas }\end{array}$ \\
\hline & & $\operatorname{SCS}^{\&}$ & Indistinct & Female & & & $\begin{array}{l}\text { Mutations in SDH genes } \\
B, C, D \text { Association with } \\
\text { paragangliomas }\end{array}$ \\
\hline & SDHA (-) & $\begin{array}{l}\text { Adults } \\
\text { and teens }\end{array}$ & 25 years & Female & & & $\begin{array}{l}\text { Mutations in SDH B, C, } \\
\text { and D genes In most } \\
\text { cases in SDH A }\end{array}$ \\
\hline
\end{tabular}

CSS: Carney-Stratakis syndrome; IGF1: insulin-like growth factor 1; IHC: immunohistochemistry; TC: carney triad; WT-GISTs: wild-type gastrointestinal stromal tumors. *In the majority of reported cases; \&familial GIST syndrome.

a known hereditary component; calculations suggest that $5 \%$ of WT-GIST are present in some familial syndromes of an oncological nature, such as the Carney-Stratakis syndrome (Carney dyad), the Carney triad, Von Recklinghausen disease or type-1 neurofibromatosis, and the primary familial GIST syndrome ${ }^{11,15}$. Given the unique characteristics of this neoplasm, it is possible to divide the tumors into syndromic (familial) and non-syndromic (sporadic) WT-GIST; nonetheless, said classification does not attend its immunohistochemical characteristics $^{8,15}$ (Fig. 1).

\section{Molecular variations for WT-GIST and physiopathology}

When comparing WT-GIST with the classic phenotype for neoplasm, the WT-GIST tumors are the recipient of a group of ambiguous heterogeneous mutations such as BRAF, NF-1, KRAS, CBL, PI3K3CA, or in dehydrogenase succinate protein (DSP subunits $A, B, C$, and $D)$, with the latter being the most common. Hence, to understand them better, they have been classified depending on the mutation of the $\mathrm{SDH}^{8,14,16-19}$ (Table 1).

Recently, Mavroeidis et al. ${ }^{9}$ analyzed the anatomopathological and molecular profiles of 38 patients diagnosed with GIST, and through sequencing of 54 tumor suppressor genes and oncogenes, they detected alterations in 33 of the cases, specifically in the following genes: BRAF (2.6\%), PIK3CA (2.6\%), KRAS (2.6\%), FGFR3 (2.6\%), PDGFRA (18.43\%), and KIT (57.89\%).

More recently, Nannini et al. ${ }^{19}$ denominated the group of tumors lacking a specific molecular event (orphans) as "quadruple-negative WT-GIST" (KIT/PDGFRA/BRAF/ $\mathrm{SDH})$, given their significant molecular heterogeneity with many different mutational events, pointing out the fact that they could represent another unique group of the GIST family.

Gasparotto et al. ${ }^{20}$ estimated that $10 \%$ of GISTs belong to the quadruple-negative WT-GIST category. However, their study reports that 59\% (13722) of cases carried pathogen mutations of the NF-1 gene, thus suggesting that a significant fraction of "sporadic" quadruple-negative WT-GISTs is, in fact, of a syndromic 
Table 2. Subtypes of very rare WT-GISTs, not dependent on succinate dehydrogenase and its characteristics. *Quadruple negative WT-GISTs

\begin{tabular}{|l|l|l|l|}
\hline Mutation & Incidence & Location & Clinical characteristics \\
\hline BRAF & $<1 \%$ & $\begin{array}{l}\text { Small } \\
\text { intestine, } \\
\text { stomach }\end{array}$ & $\begin{array}{l}\text { - Type of spindle cells } \\
- \text { KIT positive } \\
\text { - VE1 positive }\end{array}$ \\
\hline $\begin{array}{l}\text { RAS (including KRAS) } \\
\text { *PIK3CA, CBL, ETV6-NTRK3, FGFR1-H00K3, FGFR1-TACC1, } \\
\text { KIT-PDGFRA, MARK2-PPFIA1, SPRED2-NELFCD, etc. }\end{array}$ & Very rare & Nonspecific sensitive to BRAF and MEK inhibitors \\
\hline
\end{tabular}

WT-GISTs: wild-type gastrointestinal stromal tumors.

nature, since they appear in patients with non-diagnosed NF-1 (Table 2).

\section{Physiopathology}

There are four complexes (I, II, III, and IV) present in the internal mitochondrial membrane, which play a crucial role in the electron transport chain. Mitochondrial complex II, also known as succinate dehydrogenase complex, is a tricarboxylic acid heterotetrameric enzyme, composed by SDHA and SDHB, that code the catalytic enzymatic component, as well as SDHC and SDHD, which anchor the entire SDH complex to the inside of the mitochondrial membrane. The main function of this complex is to remove hydrogen atoms from the succinate for their oxidation and consequent formation of fumarate; it is particularly important in the production of energy since it participates in the Krebs cycle, as well as in the respiratory chain ${ }^{8,17,21}$.

There are somatic mutations and of the germinal line that causes a loss in function of any of the subunits of the succinate dehydrogenase complex.

SDH deficiency and the resulting accumulation of succinate promote the development of GIST through different mechanisms, including the positive regulation of HIF1 $\alpha$ and the inhibition of DNA demethylation; however, different authors consider overexposure of several nuclear genes as the main trigger, including $\mathrm{HIF} 1 \alpha$, which causes angiogenesis de-regularization, erythropoiesis, and apoptosis ${ }^{8,17,20}$ (Fig. 2).

\section{KRAS and BRAF mutations}

Although uncommon, KRAS and BRAF mutations form between $1 \%$ and $3 \%$ of GISTs. Their importance relies on the fact that they can affect the response to imatinib in those mutations sensitive to $\mathrm{KIT}^{14,22,23}$.
KRAS mutations occur in codon 12 or 13 , generating a glycine substitution which prohibits the inactivation of RAS by GAP, which maintains RAs kinase in a sustained active form ${ }^{17}$. BRAF is found in chromosome $7 \mathrm{q} 34$, and the most frequent activation mutation is in the exon 15, where the nucleotide substitution is found in position 1799 (A to T) in the kinase, which leads to a substitution of Valine for glutamic acid in codon 600 (p. V600E). To date, it is not clear which pathogenic mechanisms underlie the development of BRAF mutations; there are different subassemblies of interstitial Cajal cells, which are predisposed to different types of mutations; nevertheless, the mutation of the BRAF gene with again in function has been observed in different cancers, such as malign melanomas, colorectal carcinomas, and lung cancer ${ }^{14,23,24}$.

\section{Syndromic WT-GISTs}

\section{Von Recklinghausen's disease (type 1 neurofibromatosis)}

This is a dominant, autosomal neurocutaneous disease of low prevalence with a tendency of tumor formation in the neuroectodermal and mesodermal tissues. Phenotypically characterized by multiple "caféau-lait" spots, Lisch nodules, neurofibromas with freckles, and occasional development of malignant peripheral nerve sheath tumors, as well as GIST $8,12,25$.

In general, type 1 neurofibromatosis presents alterations in the NF1 gene located in the long arm of chromosome 17 (17q11.2) and contains 50 exons, which codify for the neurofibromin protein ${ }^{25}$. GISTs linked to NF-1 frequently prove loss of heterozygosity at $14 q$ and 22q similar to sporadic GISTs mutated by KIT and PDGFRA ${ }^{12}$. 


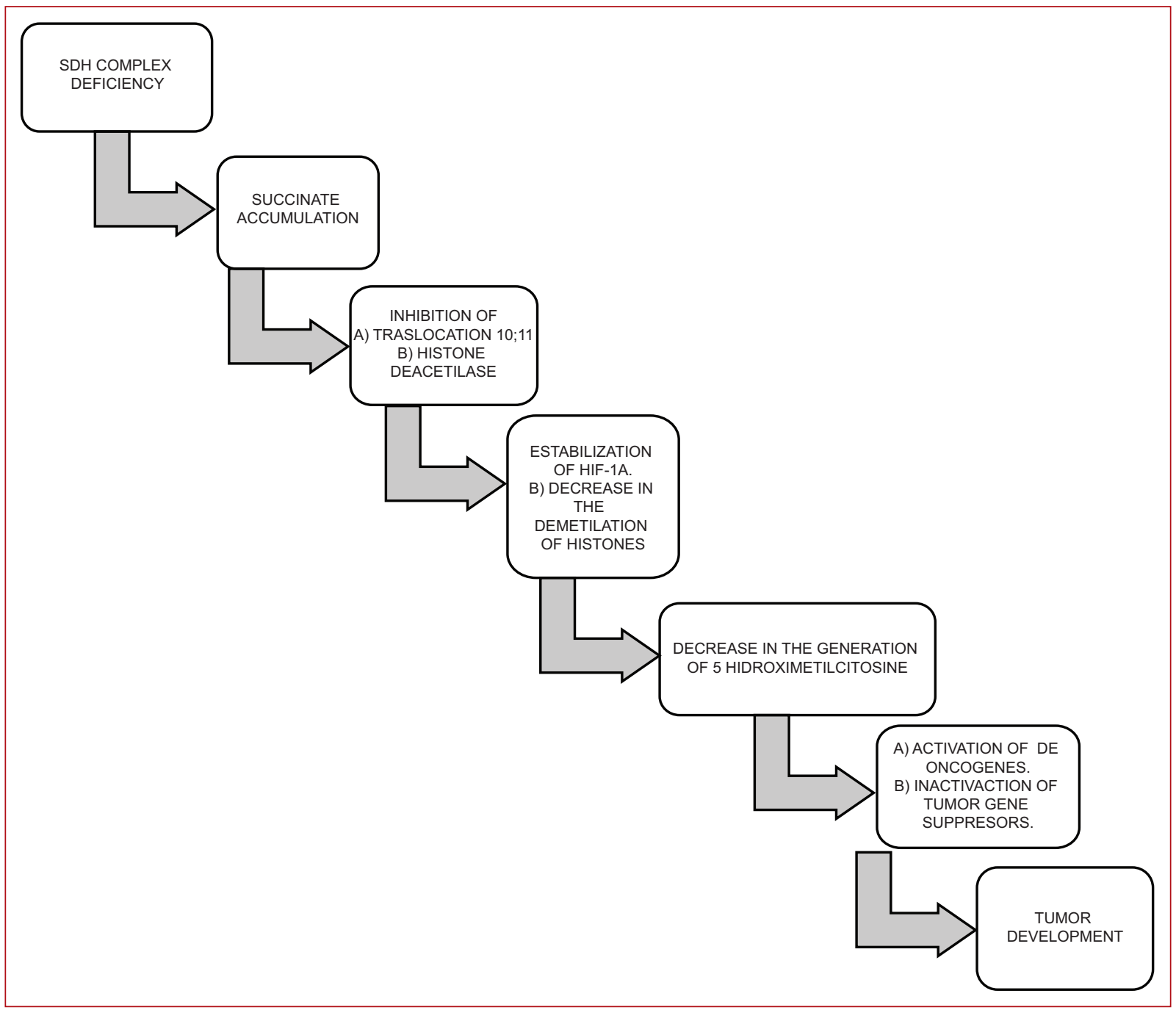

Figure 2. Molecular alterations in the pathogenesis of succinate dehydrogenase-deficient wild-type gastrointestinal stromal tumors.

\section{Carney's triad}

Described initially as gastric leiomyosarcomas (known today as gastric GISTs), pulmonary chondroma, and paraganglioma, even though the predisposition to suffer adrenocortical adenomas and pheochromocytomas has been proven. Within Carney's triad, the GIST tends to be multifocal and of gastric origin, although in some cases, the deletion of 1q12-q21 has been identified, with hyper-methylation of the SDHC promoter. Thus, in 2011, a proposal was made where those patients without SDHx mutations but with a loss of SDHB by IHC ought to be considered TC patients ${ }^{8,12}$.

\section{Carney-Stratakis syndrome}

Described in 2002 as a different entity from Carney's syndrome, characterized by the tendency of gastric GISTs and paraganglioma formation. There are two variants of this syndrome: the full form, which presents both neoplasms, and the incomplete form, where there is only the presence of gastric GIST, but with a high risk of developing paragangliomas in the future. Allele loss of chromosomal loci for SDHC has been detected, yet there are records where a defect of subunit $D$ of the dehydrogenase succinate complex has been proven ${ }^{8,12}$.

Despite having observed that GIST deficient in SDH originated in the SCS, and has inadequate responses to traditional therapy with imatinib, several studies have proven response to sunitinib ${ }^{10}$.

\section{Familial GIST syndrome}

This is an autosomal dominant disease caused by mutations in the germinal line in KIT or PDGFRA, which 
also shows up in $80-88 \%$ of cases of sporadic GIST. It represents $<5 \%$ of cases. Like sporadic GISTs, it presents mutations in the exons $8,11,1$, and 17 , but not for exon 9. In addition, alterations in the axon 11 are reported in fewer cases compared to the classic phenotype ${ }^{26,27}$.

\section{Conclusions}

Today, given the unique and indolent characteristics of this group of neoplasms, there is a need for a correct diagnosis and delimitation of the subgroup to which they belong with the sole purpose of reducing the risk of failure for the different existing therapeutic measures. Moreover, when comparing the data obtained by Medina-Medina et al., it is possible to conclude the predominance of a higher number of wild GISTs within the Mexican population, due to the preponderance of females and the younger age reported for them.

The authors consider a greater and imminent need for a greater number of studies conducted among our population, to correctly determine epidemiological data, as well as the possibility to define specific and unique characteristics for the Mexican population.

As a final comment, we insist on raising awareness within the medical population in Mexico concerning GISTs, as well as the consideration of holistic therapy for patients with this type of neoplasm. Therefore, the authors encourage the diffusion of the Mexican GIST foundation A.B.P. ${ }^{25}$ not only for the census of these patients but also for their continuous support.

We ought to acknowledge the hard work that this foundation conducts each day spreading information, and the support provided to those who suffer from GIST.

\section{Conflicts of interest}

The authors declare have no conflicts of interest.

\section{Ethical disclosures}

Protection of human and animal subjects. The authors declare that no experiments were performed on humans or animals for this study.

Confidentiality of data. The authors declare that no patient data appear in this article.

Right to privacy and informed consent. The authors declare that no patient data appear in this article.

\section{References}

1. Søreide K, Sandvik OM, Søreide JA, Giljaca V, Jureckova A, Bulusu VR Global epidemiology of gastrointestinal stromal tumours (GIST): a syste- matic review of population-based cohort studies. Cancer Epidemiol. 2016;40:39-46.

2. López-Valdés JC, Nava-Gutiérrez W, Astaburuaga-Gómez A, Pérez-Perales JE. Tumor del estroma gastrointestinal como causa de hemorragia del tubo digestivo: presentación de un caso. Cir Gen. 2015;37:99-104.

3. Medina-Medina JA, Nava-Gutiérrez W, Barrón-Reyes JE, Miranda-Hernández A, López-Valdés JC. Incidencia de los tumores del estroma gastrointestinal en la población mexicana. Gac Mex Oncol. 2018;17:40-7.

4. Calderillo G, López HN, Díaz C, Herrera M, Mendez V, Padilla A. Epidemiological Study of 414 Gastroinstestinal Stromal Tumors (GIST) Mexican Patients (Poster). World Congress of Gastroinstestinal Cancer; 2017. Available from: https://www.postersessiononline.eu/173580348_eu/congresos/19wcgic/aula/-P_159_19wcgic.pdf. [Last accessed on 2019 Jan 09].

5. Boikos SA, Pappo AS, Killian JK, LaQuaglia MP, Weldon CB, George S, et al. Molecular subtypes of KIT/PDGFRA wild-type gastrointestinal stromal tumors: a report from the national institutes of health gastrointestinal stromal tumor clinic. JAMA Oncol. 2016;2:922-8.

6. Kim SY, Janeway K, Pappo A. Pediatric and wild-type gastrointestinal stromal tumor: new therapeutic approaches. Curr Opin Oncol. 2010;22:347-50.

7. Weldon CB, Madenci AL, Boikos SA, Janeway KA, George S, von Mehren $\mathrm{M}$, et al. Surgical management of wild-type gastrointestinal stromal tumors: a report from the national institutes of health pediatric and wildtype GIST clinic. J Clin Oncol. 2017;35:523-8.

8. Jahn SW, Liegl-Atzwanger B. Wild-type GIST: a comprehensive review. Memo. 2014;7:34-8

9. Mavroeidis L, Metaxa-Mariatou V, Papoudou-Bai A, Lampraki AM, Kostadima L, Tsinokou I, et al. Comprehensive molecular screening by next generation sequencing reveals a distinctive mutational profile of PDGFRA genes and novel genomic alterations: results from a 20 -year cohort of patients with GIST from north-western Greece. ESMO Open. 2018;3:e000335.

10. Rutkowski $\mathrm{P}$, Magnan $\mathrm{H}$, Chou AJ, Benson $\mathrm{C}$. Treatment of gastrointestinal stromal tumours in paediatric and young adult patients with sunitinib: a multicentre case series. BMC Cancer. 2017;17:717.

11. Rink L, Godwin AK. Clinical and molecular characteristics of gastrointestinal stromal tumors in the pediatric and young adult population. Curr Oncol Rep. 2009;11:314-21.

12. Miettinen M, Lasota J, Sobin LH. Gastrointestinal stromal tumors of the stomach in children and young adults: a clinicopathologic, immunohistochemical, and molecular genetic study of 44 cases with long-term follow-up and review of the literature. Am J Surg Pathol. 2005;29:1373-81.

13. Miettinen M, Fetsch JF, Sobin LH, Lasota J. Gastrointestinal stroma tumors in patients with neurofibromatosis 1: a clinicopathologic and molecular genetic study of 45 cases. Am J Surg Pathol. 2006;30:90-6.

14. Wada R, Arai H, Kure S, Peng WX, Naito Z. "Wild type" GIST: clinicopathological features and clinical practice. Pathol Int. 2016:66:431-7.

15. Gopie P, Mei L, Faber AC, Grossman SR, Smith SC, Boikos SA. Classification of gastrointestinal stromal tumor syndromes. Endocr Relat Cancer. 2018:25:R49-58

16. Nishida T. Therapeutic strategies for wild-type gastrointestinal stromal tumor: is it different from or mutated GISTs? Transl Gastroenterol Hepatol. 2017;2:92.

17. Mou $Y$, Wang $Q$, Li B. The "wild"-type gastrointestinal stromal tumors: heterogeneity on molecule characteristics and clinical features. Cancer Transl Med. 2018;4:75-82.

18. Postow MA, Robson ME. Inherited gastrointestinal stromal tumor syndromes: mutations, clinical features, and therapeutic implications. Clin Sarcoma Res. 2012;2:16.

19. Nannini M, Urbini M, Astolfi A, Biasco G, Pantaleo MA. The progressive fragmentation of the KIT/PDGFRA wild type (WT) gastrointestinal stromal tumors (GIST). Transl Med. 2017;15:113.

20. Gasparotto D, Rossi S, Polano M, Tamborini E, Lorenzetto E, Sbaraglia M, et al. Quadruple-negative GIST is a sentinel for unrecognized neurofibromatosis Type 1 syndrome. Clin Cancer Res. 2017;23:273-82.

21. Ricci R, Dei Tos AP, Rindi G. GISTogram: a graphic presentation of the growing GIST complexity. Virchows Arch. 2013;463:481-7.

22. Huss $S$, Pasternack $H$, Ihle MA, Merkelbach-Bruse S, Heitkötter B, Hartmann W, et al. Clinicopathological and molecular features of a large cohort of gastrointestinal stromal tumors (GISTs) and review of the literature: BRAF mutations in KIT/PDGFRA wild-type GISTs are rare events. Hum Pathol. 2017;62:206-14.

23. Valdéz JC. Tumores neuroendocrinos gastroenteropancreaticos: revisión de la literatura. Rev Esc Med J Sierra. 2012;26:31-6.

24. Miranda C, Nucifora M, Molinari F, Conca E, Anania MC, Bordoni A, et al. KRAS and BRAF mutations predict primary resistance to imatinib in gastrointestinal stromal tumors. Clin Cancer Res. 2012;18:1769-76.

25. Forde PM, Cochran RL, Boikos SA, Zabransky DJ, Beaver JA, Meyer CF et al. Familial GI stromal tumor with loss of heterozygosity and amplification of mutant KIT. J Clin Oncol. 2016;34:e13-6.

26. Jones DH, Caracciolo JT, Hodul PJ, Strosberg JR, Coppola D, Bui MM. Familial gastrointestinal stromal tumor syndrome: report of 2 cases with KIT exon 11 mutation. Cancer Control. 2015;22:102-8.

27. Fundación GIST México. Available from: http://www.fundaciongist.org [Last accessed on 2019 Jan 09]. 